\title{
Efficacy of Micronutrients in Influencing Growth Behavior of Rhizobium of Pigeonpea (Cajanus cajan L. [Millsp.])
}

\author{
SONAM PALIYA ${ }^{1}$, A.N. TIKLE ${ }^{1 *}$ and TESSY THOMAS ${ }^{2}$ \\ ${ }^{1}$ Rafi Ahmed Kidwai College of Agriculture Sehore - 466, India. \\ ${ }^{2}$ Government P.G. Nodal college Sehore - 466 001, India. \\ ${ }^{*}$ Corresponding author E-mail: antiklepb@gmail.com \\ http://dx.doi.org/10.13005/ojc/300245
}

(Received: March 30, 2014; Accepted: May 01, 2014)

\begin{abstract}
The present investigation was conducted to observe the effect of various concentrations ( 0.1 to $1.5 \mathrm{gm} / 100 \mathrm{ml})$ of micronutrients $(\mathrm{Zn}, \mathrm{Mn}, \mathrm{B}, \mathrm{Cu}, \mathrm{Mo}, \mathrm{Fe})$ with yeast extract mannitol media on agriculturally important Rhizobium species isolated from root nodules of Cajanus cajan and to determine the effect of multi-micronutrient yeast extract mannitol media prepared of maximum growth concentrations of micronutrients on rhizobial growth. Concentrations of $\mathrm{Zn}(0.1 \%), \mathrm{Mn}(0.3 \%)$, $\mathrm{B}(0.1 \%)$, and $\mathrm{Mo}(0.1 \%)$ with yeast extract mannitol media composition represented increased number of CFU against control. The growth of Rhizobium in multimicronutrient yeast extract mannitol media decreased by $25 \%$ compared to control.
\end{abstract}

Key words: Cajanus cajan, Rhizobium, Micronutrients, Yeast extract mannitol media, Root nodules.

\section{INTRODUCTION}

Trace elements are essential for key physiological activity of photosynthesis and respiration'. Metals such as copper, zinc comprise as trace elements for redox process to balance molecules through electrostatic interaction, as a part of many enzymes and for standardization of osmotic pressure $^{2}$. The combination of microelements in soil suspension confides on the physical and chemical characteristic specifically $\mathrm{pH}$ and $\mathrm{PE}{ }^{3}$. Zinc accomplishes as trace mineral as well as it also plays roll as circumstantial poisonous constituent, influences nodulation and nitrogen fixation ${ }^{485}$.
Boron is a necessary micronutrient required for routine plant growth ${ }^{6}$. Insufficiency of boron leads to aberrant nodule formation with convincing minimization of infection?

Rhizobium is one of the valuable bacterium species, which fixes $50 \%$ of 175 million tons of total biological N2 annually worldwide with legume species ${ }^{8}$. Chick pea and Rhizobium leguminous symbiotic association per year harvest up to $176 \mathrm{~kg} \mathrm{~N} / \mathrm{ha}-1$ which depends on bacterial strain and circumstantial determinants ${ }^{9810}$. The bacteria of the genus Rhizobium is an inherently varying and physiologically heterogenus faction of 
microbes which has the potentiality to nodulate leguminaceae family plants ${ }^{11}$. Rhizobium has the capability to convert atmospheric N2 into ammonia by symbiotic association which is again transferred and taken up by the plants ${ }^{3}$. In crop species, induction of root nodules is affected by various atmospheric determinants ${ }^{12}$.

The common media used for culturing rhizobia is yeast extract mannitol media, which is made up of yeast extract powder or pastes ${ }^{13}$. Yeast extract mannitol media is found to be best suiting nutrient media for Rhizobium growth. The ideal medium contains mannitol and sucrose as the source of nitrogen, growth factors and mineral salts $^{14}$.

Other than these elements for the appropriate growth of rhizobia, search of other required elements are also essential. Thus, the object of this work is to find out the effect of other trace elements on rhizobia, by which they can be incorporated in media for Rhizobium.

\section{MATERIALS AND METHOD}

Isolation of Rhizobium from root nodules of pigeonpea

Pigeonpea plants were collected from pigeonpea research experimental area of College of Agriculture Sehore and root nodules were separated. The nodules were washed under running tap water, surface sterilized using liquid detergent $2 \%(\mathrm{~V} / \mathrm{V})$ Savlon, then treated in 6 drops of tween 20 for $15 \mathrm{~min}$, rinsed with $70 \%$ ethanol for $30 \mathrm{sec}$ and disinfected by $0.05 \%(\mathrm{~W} / \mathrm{V}) \mathrm{HgCl}_{2}{ }^{15}$. After sterilization, nodules were crushed with a sterile glass-rod and suspension was serially diluted to $10^{-9}$ dilution. $0.1 \mathrm{ml}$ of each dilution was spread on Petri-plate containing yeast extract mannitol agar media (YEMA). The inoculated plates were incubated in BOD incubator at $37 . \mathrm{C}$ for 2 to 3 days.

Preparation of yeast extract mannitol agar with different concentrations of micronutrients

The normal culture media for isolation and proper growth of Rhizobium is Yeast Extract Mannitol Agar with Congo red. YEMA (/L) (control) contains $\mathrm{K}_{2} \mathrm{HPo}_{4}(0.5 \mathrm{~g})$, Nacl $(0.1 \mathrm{~g}), \mathrm{MgSO} 4 \times 7 \mathrm{H} 2 \mathrm{O}$ $(0.2 \mathrm{~g}), \mathrm{CaCO}_{3}(3 \mathrm{~g})$, Mannitol $(10 \mathrm{~g})$, yeast extract (0.2g), Congo red (2.5ml) (1\% W/V), Agar (12 g). Congo red is an indicator for isolation and has capacity to inhibit gram positive organism.

As a source of micronutrients ( $\mathrm{Zn}, \mathrm{Mn}, \mathrm{B}$, $\mathrm{Cu}, \mathrm{Mo}, \mathrm{Fe})$, salts of these elements were used i.e. $\mathrm{ZnSO}_{4}, \mathrm{MnO}, \mathrm{H}_{3} \mathrm{BO}_{3}, \mathrm{CuSO}_{4}, \mathrm{AmMo}_{\mathrm{N}} \mathrm{FeSO}_{4}$. To prepare the concentrations $(0.1,0.3,0.5,0.7,0.9$, 1.0, 1.1, 1.3 and 1.5) of micronutrients, composition of basic Yeast Extract Mannitol media was added with $100 \mathrm{ml}$ distilled water, and in the above prepared composition a concentration was mixed from the above concentration of micronutrients and thus each concentration of all the micronutrients was prepared with YEMA. Prepared control and micronutrient medium were autoclaved at $121^{\circ} \mathrm{C}$ for 20 minutes.

Each media plate was inoculated by spread plate technique from Rhizobium culture and plates were incubated for 2-3 days.

\section{Preparation of multi-micronutrient Yeast Extract Mannitol media (YEM)}

Concentrations $(\mathrm{g} / 100 \mathrm{ml})$ of micronutrients those exhibited increased number of CFU against the control were dissolved in $100 \mathrm{ml}$ distilled water with YEM composition. This multi-micronutrient yeast extract mannitol broth media was inoculated with Rhizobium culture and was allowed to incubate on rotatory shaker at $37^{\circ} \mathrm{C}$ for $4-7$ days. For viability test, $0.1 \mathrm{ml}$ of the multi-micronutrient broth culture was spread on YEMA plates and incubated for 2-3 days.

All the experiments were repeated at three times and following formula was used to calculate the number of colonies formed:

\section{(Colony Forming Unit) $=$ number of colonies * inverse dilution * 10}

\section{RESULT AND DISCUSSION}

In present investigation, colony counts on effect of micronutrient (Table -1 ) revealed that $0.1 \%$ Zinc (5711.66 \pm 173.00$), 0.3 \%$ Manganese $(5771.33 \pm 6.79), 0.1 \%$ Boron $(6127 \pm 5.25)$ (Fig 1), $1.5 \%$ Copper (4522.33 \pm 7.68$), 0.1 \%$ Molybdenum $(6485.66 \pm 11.10), 0.3 \%$ Iron $(4456 \pm 7.28)$ were the most efficacious concentrations with yeast 


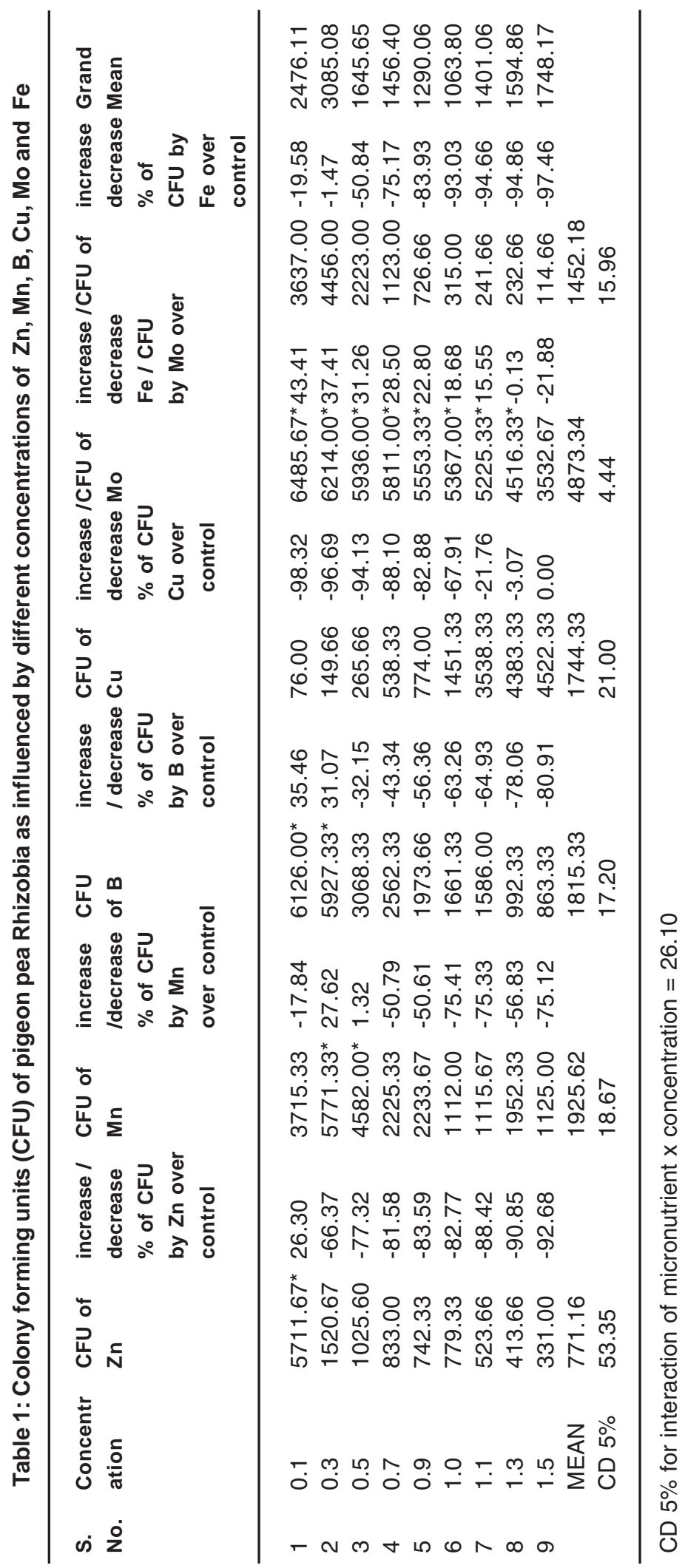


Table 2: Percent increase in CFU of rhizobia by multi-micronutrient media over individual best micronutrient

\begin{tabular}{lccc}
\hline S. & $\begin{array}{c}\text { Concentration of individual } \\
\text { best micronutrient and } \\
\text { molti-micronutrient }\end{array}$ & CFU count & $\begin{array}{c}\text { Percent increase in CFU by } \\
\text { multi-micronutrient media }\end{array}$
\end{tabular}

\begin{tabular}{lccc}
\hline 1 & $0.1 \% \mathrm{Zn}$ & 5711.67 & 22.03 \\
2 & $0.3 \% \mathrm{Mn}$ & 5771.33 & 20.76 \\
3 & $0.1 \% \mathrm{Bo}$ & 6126.00 & 13.77 \\
4 & $0.1 \% \mathrm{Mo}$ & 6484.67 & 07.48 \\
5 & Mean & 6023.41 & 15.71 \\
6 & Multi-micronutrient & $6970.00^{*}$ & - \\
& $\mathrm{SD} \pm$ & 475.54 & \\
\hline
\end{tabular}

extract mannitol media to Rhizobium growth, and exhibited maximum number of population against rest of the concentrations in terms of CFU. However the highest CFU $(6485.66 \pm 11.10)$ was recorded in $0.1 \%$ Molybdenum concentration (Fig 2).

The maximum growth of $5711.66 \mathrm{CFU}$ was recorded in $0.1 \%$ concentration of zinc (Fig 1 ). With increase in concentration thereafter, there was a significant drastic decrease in Rhizobium count.

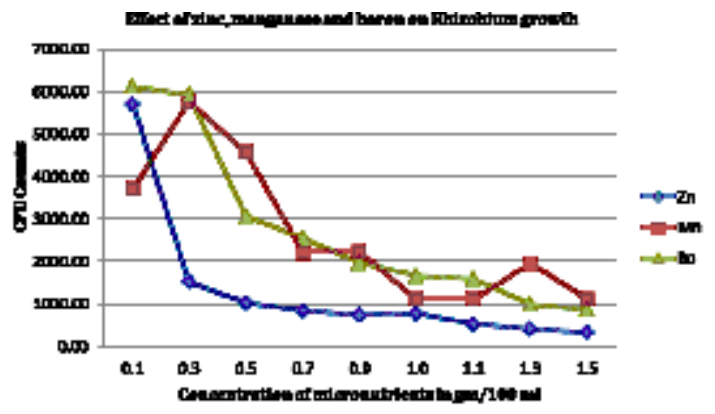

Fig. 1: Growth behavior of Rhizobium influenced by zinc, manganese and boron concentration $(\mathrm{gm} / 100 \mathrm{ml})$

Through the application of boron the higher CFU count (6126.00), was observed in $0.1 \%$ application which was 35.46 percent higher than the control (Fig 1). The next dose of $0.3 \%$, although had significant growth rate of 31.07 percent over the control, but this growth was neither at par or superior over $0.1 \%$ application of boron.
Increase in the concentration of manganese from $0.1 \%$ to $0.3 \%$ significantly increased the CFU count (5771.33) by 27.62 percent over the control (4522.33) (Fig 1). Increase the manganese concentration to the level of $0.5 \%$ also had significant CFU count (4582.00) as compared to the mean concentrations of manganese (1925.62). Although this increase in CFU is significantly greater than control, the percent increase is meager (1.32 percent) (Table 1).

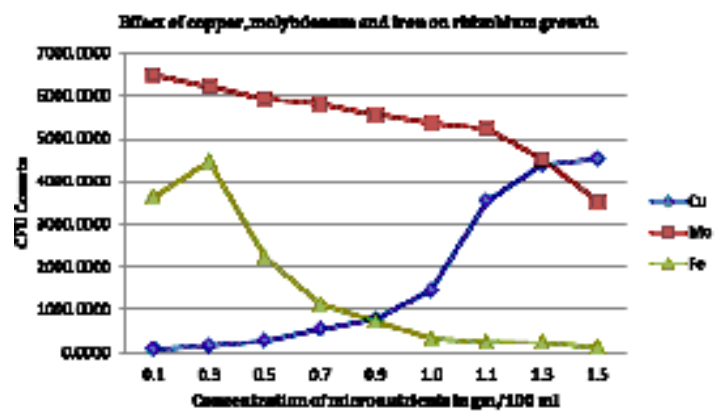

Fig. 2: Growth behavior of Rhizobium influenced by copper, molybdenum and iron concentration $(\mathrm{gm} / 100 \mathrm{ml})$

As regard the effect of copper, there was a linear increase in CFU of rhizobia from 76.00 to 4522.33 , with the increase in concentration from $0.1 \%$ to $1.5 \%$ respectively. However the highest CFU (4522.33) was equal to the control (Fig 2) (Yeast extract mannitol media). It seems that copper did not have influential role to increase rhizobia population. 
Molybdenum plays a vital role in nodulation and nodule growth in leguminous crops, because, it is constituent of the nitrogenase enzyme for every bacterium which fixes nitrogen. Also, molybdenum enhances plant growth as well as seed yield and mineral composition ${ }^{16}$ The concentration of $0.1 \%$ molybdenum has superiority of enhancing rhizobium CFU to the maximum of 6485.67. This increase is not only significantly superior amongst the concentrations of molybdenum; it also has the superiority over all other elements used in this study (Fig 2). It was closely followed by $0.3 \%$ concentration of molybdenum (6214.00 CFU count). There was only a 6 percent decrease of CFU count as compare to $0.1 \%$ concentration of molybdenum. It is also evidence that application of molybdenum at the rate of $1 \mathrm{~kg} /$ ha as soil application and $1 \mathrm{gm} / \mathrm{kg}$ of as seed coating enhance the nodules numbers and nodule weight in chickpea $^{17}$

A reduction in specific rates of nitrogenase activity has been observed in iron limited peanut nodules indicating a possible direct limitation by iron deficiency on nodule function ${ }^{18}$. In the present study, as per the activity of manganese, the iron also showed enhanced growth from $0.1 \%$ concentration to $0.3 \%$ concentration and thereafter decreased (Fig 2). However it did not show any incremental effect on enhancement of rhizobium count by increasing the iron concentration further.

Multi-micronutrient broth prepared from the best individual concentrations of zinc, manganese, boron and molybdenum, when used for rhizobium growth, it enhance the CFU count to highest of 6970.00 (Table 2). The percent increase in CFU was highest of $22.03 \%$ over 0.1 percent zinc. It was 7.48 percent higher than the best individual micronutrient i.e. molybdenum (6484.67). This increase in CFU count, even over the best individual component (molybdenum) was significantly higher (Table 2).

The quantum of quality Rhizobium is a very basic requirement to enhance the production of food legumes in Asian continent, especially in India, because large population solely depends upon food legumes for their protein requirement the small quantity of micronutrients can trigger the enhancement in Rhizobium production, which would be the cost effective and economically viable it may also increase the plant vigor at seedling stage enabling the plants to survive better. This study can further be rectified by using various cross combinations of micronutrients, so that further effective cross combinations can be worked out.

\section{REFERENCES}

1. Marschner H., Mineral nutrition of higher plants. Ed. San Diego, Academic Press. 1995; 889.

2. Gauri, Singh A.k., Bhatt R.P. and Pant S., Effects of zinc on cell viability and surface components of rhizobium species isolated from root nodules of Trifolium dexandrium. J. Agric. Technol., 2012; 8(3): 941-959.

3. Niste M., Vidican R., Rotar I., Pop R., Characterization of the growth of Rhizobium trifoli and Sinorhizobium melitoli in different culture media. Bulletin UASMV Serie Agriculture, 2013; 70(1): 80-86.

4. Munns D.N., Mineral nutrition and the legume symbiosis, In:Hardy RWF, Gibson. A.H. eds. A. section IV, New York, USA. John Wiley and sons, 1977; 353-391.
5. Smith F.W., Mineral nutrition of legumes. In: Vicent J.M. ed. Nitrogen fixation in legumes. Sydney Australia: Academic Press. 1982; 155-172.

6. Bolanos L., Elvira Esteban, Gistina De Lorenzo, Mercedes Fernandez- Pascual, Maria R.De Felipe, Garate A. and Bonilla I., Essentiality of boron for symbiotic dinitrogen fixation in pea (Pisum sativumm) rhizobium nodules. Plant Physiol. 1994; 104: 85-90.

7. Reguera Maria, Bonilla I., Bolanos L., Boron deficiency results in induction of pathogenesis related proteins from the PR10 family during the legume- rhizobia interaction. J. Plant Physiol. 167: 625-632 (2009).

8. Sarioglu G., Ozcellik S., Kaymaz S., 
Selection of effective nodosity bacteria (Rhizobium leguminosarum biovar. Viceae) from lentil grown in Elazig. Turk J Agric For 1993; 17: 569-573.

9. Rupela O.P., Saxena M.C., Nodulation and nitrogen fixation in Chickpea. In: The chick pea (Eds. M.C. Saxena, K.B. Singh). AB International, Wallingford, Oxon, 1987; 191206.

10. Beck D.P., Wery J, Saxena MC, Ayadi A., Dinitrogen fixation and nitrogen balance in cool- season food legumes. Agron. J. 1991; 83: 334-341.

11. Somasegaran P., and Hoben H.J., Methods in legume-rhizobium technology.University of Hawaii NifTAL Project and MIRCEN. Department of Agronomy ans Soil Science.

12. Richardson A.E., Simpson R.J., Djordjevic M.A., and Rolfe B.G., Expression of nodulation genes in Rhizobium leguminoserum biovar trifolli is affected by low $\mathrm{pH}$ and by $\mathrm{Ca}$ and $\mathrm{Al}$ lon. Appl. Environ. Microbiol. 1988; 54(10): 2541-2548.

13. Sherwood, Marie T., Inhibition of Rhizobium trifoli by yeast extract or glycine is prevented by calcium. J.General Microbiol. 1972; 71 : 351-358.

14. Singh A.K., Gautam G.D. and Bedi M.K., Optimization of dairy sludge for growth of rhizobium cells. Bio Med Research International, 2013.

15. Nagananda G.S., Das A., Bhattacharya S. and Kalpana T., In vitro studies on Jthe effects of biofertilizers (azotobacter and rhizobium) on seed germination and development Trigonella foenum- graecum I. using novel glass marble containing liquid medium. Int. J. Bot., 2010; 6(4): 394-403.

16. Gad Nadia and Abd El-Moez M.R., Influenced of molybdenum on nodulation, nitrogen fixation and yield of cowpea. J. App. Sci. Res., 2013; 9(3): 1498 - 1504.

17. Gupta S.C. and Gangwar S., Effect of molybdenum, iron and microbial inoculants on symbiotic traits, nutrient uptake and yield of chickpea, journal of food legumes, 2012; 25(1): 45-49.

18. O'Hara G.W., Boonkerd N., Dilwarth M.J., Mineral constraints to nitrogen fixation, Plant Soil, 1988; 108: 93-110. 